\title{
Process capability improvement of an engine connecting rod machining process
}

\author{
GVSS Sharma $^{1 *}$ and P Srinivasa Rao ${ }^{2}$
}

\begin{abstract}
Statistical process control is an excellent quality assurance tool to improve the quality of manufacture and ultimately scores on end-customer satisfaction. SPC uses process monitoring charts to record the key quality characteristics (KQCs) of the component in manufacture. This paper elaborates on one such $\mathrm{KQC}$ of the manufacturing of a connecting rod of an internal combustion engine. Here the journey to attain the process potential capability index $\left(C_{p}\right)$ and the process performance capability index $\left(C_{\mathrm{pk}}\right)$ values greater than 1.33 is elaborated by identifying the root cause through quality control tools like the cause-and-effect diagram and examining each cause one after another. In this paper, the define-measure-analyze-improve-control (DMAIC) approach is employed. The definition phase starts with process mapping and identifying the KQC. The next phase is the measurement phase comprising the cause-and-effect diagram and data collection of KQC measurements. Then follows the analysis phase where the process potential and performance capability indices are calculated, followed by the analysis of variance (ANOVA) of the mean values. Finally, the process monitoring charts are used to control the process and prevent any deviations. By using this DMAIC approach, standard deviation is reduced from 0.48 to 0.048 , the $C_{p}$ values from 0.12 to 1.72 , and the $C_{p k}$ values from 0.12 to 1.37 , respectively.
\end{abstract}

Keywords: Key quality characteristic; Cause-and-effect diagram; Statistical process control; Process monitoring charts; Failure modes and effects analysis; Analysis of variance

\section{Introduction}

One of the major manufacturing processes in engine manufacturing is that of connecting rod manufacturing. This paper implements the define-measure-analyzeimprove-control (DMAIC) approach to improve the capability of connecting rod manufacturing process by reducing the thickness variations from a nominal value.

Process mapping and identifying key quality characteristics (KQCs) is carried out in the 'definition phase', while estimation of process capability indices is carried out in the 'measure phase'. The one-way analysis of variance (ANOVA) method of investigation to test for the differences between the manufacturing data is employed in the 'analysis phase'. Finally, the process monitoring chart (PMC) for the thrust face thickness is employed in the 'improve and control phase'.

\footnotetext{
* Correspondence: sarma.gvss@gmail.com

'Department of Mechanical Engineering, GMR Institute of Technology, GMR Nagar, Rajam-532127, Andhra Pradesh State, India

Full list of author information is available at the end of the article
}

Statistical process control studies form the basic tool for obtaining the required process capability confidence levels. The various process capability indices are defined as follows:

$$
\begin{aligned}
& C_{\mathrm{P}}=\frac{\mathrm{USL}-\mathrm{LSL}}{6 \sigma} \\
& C_{\mathrm{PKU}}=\frac{\mathrm{USL}-\mu}{3 \sigma} \\
& C_{\mathrm{PKL}}=\frac{\mu-\mathrm{LSL}}{3 \sigma} \\
& C_{\mathrm{PK}}=\min \left\{\frac{\mathrm{USL}-\mu}{3 \sigma}, \frac{\mu-\mathrm{LSL}}{3 \sigma}\right\}
\end{aligned}
$$

where USL and LSL are the upper and lower specification limits, $\mu=$ process mean, and $\sigma=$ standard deviation.

The term $C_{\mathrm{p}}$ denotes the process potential capability index, and similarly, the term $C_{\mathrm{pk}}$ denotes the process performance capability index. $C_{\mathrm{p}}$ gives an indication of

\section{实}

(C) 2013 Sharma and Rao; licensee Springer. This is an open access article distributed under the terms of the Creative Commons Attribution License (http://creativecommons.org/licenses/by/2.0), which permits unrestricted use, distribution, and reproduction in any medium, provided the original work is properly cited. 
the dispersion of the product dimensional values within the specified tolerance zone during the manufacturing process. Similarly, the index $C_{\mathrm{pk}}$ denotes for the centering of the manufacturing process with respect to the mean of the specified dimensional tolerance zone of the product. $C_{\mathrm{pk}}$ gives us an idea on whether the manufacturing process is performing at the middle of the tolerance zone or nearer the upper or lower tolerance limits. If the manufacturing process is nearer the lower limit, then the process performance capability index is given by $C_{\mathrm{pkl}}$, and if the manufacturing process is nearer the upper limit, then the process performance capability index is given by $C_{\mathrm{pku}}$. As a measure of precautionary safety, the minimum value between the two is taken as the value of $C_{\mathrm{pk}}$.

\section{Literature survey}

The literature survey of process capability improvements using the DMAIC approach is discussed in this section. Schilling (1994) emphasized how process control is better than the traditional sampling techniques. During the same era, Locke (1994), in his paper titled 'Statistical measurement control', emphasized the importance of process charts, cause-and-effect considerations, and control charting. After primitive studies on statistical quality control, Lin (2004) had shed some light on process capability indices for normal distribution. Tong et al. (2004) suggested that a DMAIC approach is useful for printed circuit board quality improvement. They also proved how design of experiments is one of the core statistical tools for six-sigma improvement. Subsequently, Li et al. (2008) once again proved the importance of DMAIC approach to improve the capability of surface mount technology in a solder printing process. Hwang (2006) discussed the DMAIC phases in detail with application to manufacturing execution system. Gentili et al. (2006) applied the DMAIC process to a mechanical manufacturing process line, which manufactures both professional and simple kitchen knives. Sahay et al. (2011) once again brought the DMAIC approach into use to analyze the manufacturing lines of a brake lever at a Connecticut automotive component manufacturing company. Singh (2011) investigated the process capability of polyjet printing for plastic components. In his observation, he traveled the improvement journey of the process of critical dimensions and their $C_{\mathrm{pk}}$ value attainment greater than 1.33, which is considered to be an industrial benchmark. In recent studies conducted by Lin et al. (2013), they focused on turbine engine blade inspection as it is a key aspect of engine quality. They elaborated on the accurate yield assessment of processes with multiple characteristics like the turbine blade manufacturing process. Kumaravadivel and Natarajan (2013) dealt with the application of the six-sigma methodology to the flywheel casting process. The primary problem solving tools used were the process map, cause-and-effect matrix, and failure modes and effects analysis (FMEA). Sharma et al. (2013a), b in their papers adopted the DMAIC approach to solve the bolt hole center distance and crankpin bore honing operations of the connecting rod manufacturing process. Chen et al. (2013) discussed the application of ANOVA methodology to find significant parameters that affect the part's quality indices with respect to plastic injection molding.

A careful study from the above literature reveals that the DMAIC approach is the best methodology for problem solving tools to improve the manufacturing process capability levels. Hence, this paper focuses on the application of DMAIC approach for process capability improvement of the crankpin bore honing operation of an engine connecting rod manufacturing process.

\section{Definition phase}

The definition phase starts with the correct mapping of the machining process flow of the connecting rod.

\section{Process mapping}

The process flow chart for the machining line of the connecting rod machining cell consisted of the following machining operation sequence shown in Figure 1. Table 1 describes the machining operations of the connecting rod manufacturing cell.

\section{Identifying KQCs}

The acceptable thrust face thickness variation of the connecting rod forgings was limited from $0.5 \mathrm{~mm}$ to a maximum of $1 \mathrm{~mm}$. The forgings from these tolerance limits resulted in a thrust face 'unclean' problem and were subsequently rejected. This caused costly repair and rework. Hence, in this regard, this research aims at improving the connecting rod manufacturing process by reducing the thrust face thickness variations early in the stages of the machining process line so that these variations are not carried to the subsequent machining operations down the manufacturing line. Hence, thrust face thickness was of the main concern and identified as a KQC, whose value is equal to $27.000^{(+0.500 / 0.000)} \mathrm{mm}$. Figure 2 depicts a diagrammatic view of this key process characteristic (KQC).

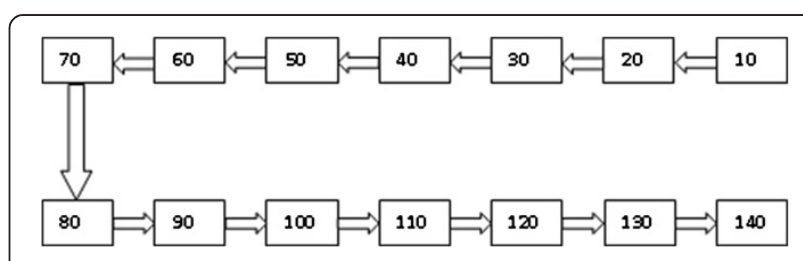

Figure 1 Process flow chart. Refer to Table 1 for the corresponding descriptions of the operations. 


$\begin{aligned} & \text { Table } 1 \text { Machining operations of the connecting rod } \\
& \text { manufacturing cell }\end{aligned}$
\begin{tabular}{ll} 
Machining & Description \\
operation number & \\
\hline 10 & Thrust face rough grinding \\
20 & Gudgeon pin rough boring \\
30 & Crankpin rough boring \\
40 & Side face broaching \\
50 & Finish grinding \\
60 & Bolt hole drilling \\
70 & Key way milling \\
80 & Rod and cap assembly \\
90 & Finish grinding of assembly \\
100 & Finish boring of gudgeon pin \\
110 & Finish boring of crankpin \\
120 & Crankpin bore honing \\
130 & Magnetic crack detection \\
140 & Final quality check, set making, and dispatch to \\
& engine assembly line \\
\hline
\end{tabular}

\section{Measurement phase}

In this phase, the thrust face thickness data of 30 nominal consecutive readings is collected and plotted on the process monitoring chart. This data collection was performed in four iterations. In each iteration, the data set of thrust face width measurement readings is taken and analyzed for $C_{\mathrm{p}}$ and $C_{\mathrm{pk}}$ values and followed by the suitable corrective action. The corrective action was decided based on the cause-and-effect diagram. After the corrective action was implemented, the next iteration was performed. This procedure was continued until the $C_{\mathrm{p}}$ and $C_{\mathrm{pk}}$ values are greater than or equal to 1.33 , i.e., up to $4 \sigma$ quality level as decided by the management of the engine manufacturing plant.

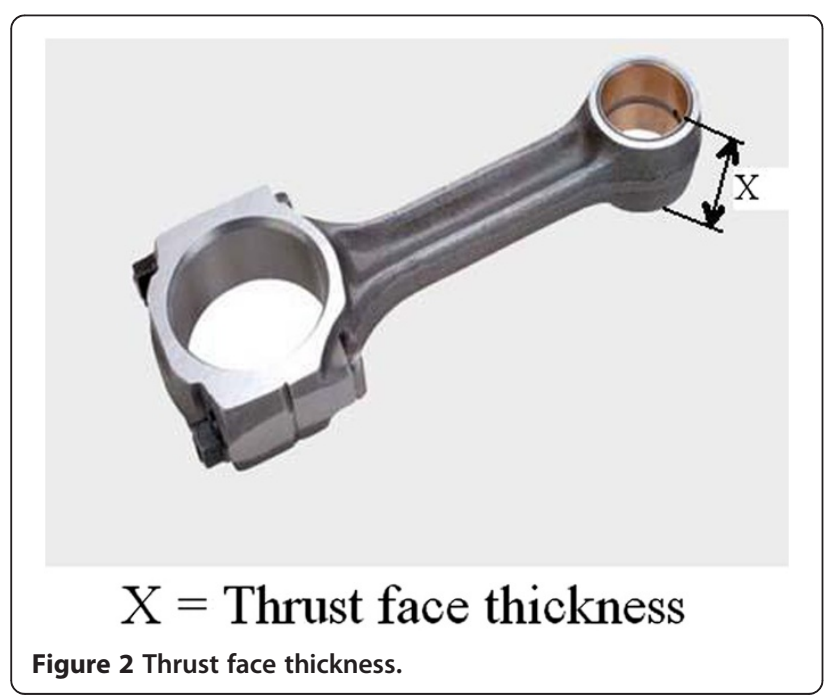

\section{Cause-and-effect diagram}

The key process characteristic identified was the thrust face thickness which is equal to $27.000^{(+0.500 / 0.000)} \mathrm{mm}$ whose machining tolerance zone is equal to $0.500 \mathrm{~mm}$. The $C_{\mathrm{p}}$ value, i.e., the process potential capability index, $\left\{C_{\mathrm{p}}=(\mathrm{USL}-\mathrm{LSL}) / 6 \sigma\right\}$, was nominally equal to 0.2 , which was far below the acceptance level limit greater than 1.33 for the above KQC. The first part of the measurement phase investigation was to track down and differentiate the common causes and special causes involved. For doing so, the cause-and-effect diagram was employed, as shown in Figure 3.

\section{Machine setup}

The machine employed was a vertical grinding machine which consisted of in-process sensors which sensed the amount of material removed during the grinding process. Figure 4 shows a picture of the machine loading and unloading platform.

\section{Process failure modes and effects analysis}

A FMEA sheet for thrust face thickness is shown in Table 2. From the causes enumerated in the cause-andeffect diagram, the failure modes and effects analysis was performed keeping in view the KPC under study. The risk priority numbers which were above 100 (as per the decision of the management) were considered to be the criteria for implementing the corrective action. It can be noticed that the highest risk priority number (RPN) is for in-process sensing gauge malfunction, followed by improper grinding wheel dressing and worn-out fixture rest pads. Hence, to mitigate these causes, a necessary action plan was devised. After performing the necessary action, the potential process FMEA was once again performed, and the risk priority numbers were recalculated until they attained a RPN below the 100 level mark.

\section{Data collection}

Data collection of the key process characteristic was performed for 32 consecutive machined components. Data collection was performed in four iterations spanning a period of 3 weeks, i.e., about 2,500 consecutive components. The data is tabulated in Table 3 . The data in Table 3 was plotted on the process monitoring chart with the number of components in the $x$-axis and component dimension on the $y$-axis and is shown in Figure 5.

\section{Analysis phase}

The analysis phase comprises performing the calculations for the $C_{\mathrm{p}}$ and $C_{\mathrm{pk}}$ values across each iteration. This was followed by one-way ANOVA method of investigation to test for the differences between the four iterations of the data sets. 




Figure 3 Cause-and-effect diagram showing the variables affecting the thrust face thickness.

Calculations of $C_{p}$ and $C_{p k}$

The calculations of $C_{\mathrm{p}}$ and $C_{\mathrm{pk}}$ are tabulated in Table 4. From the process monitoring charts and the calculations in Table 4, the following sections are the analysis done for the data set of each iteration.

\section{Iteration 1}

The first set of the statistical process capability study is composed of the raw data of the KQC, which depicted the transparent picture of the state of the existing problem. Continuous set of readings of the connecting rod after grinding operation no. 10 were captured with the help of a dial gauge on a metrological surface plate. Hence, it is seen here in the first iteration of statistical process control (SPC) studies that the process is not capable, and the $C_{\mathrm{p}}$ and $C_{\mathrm{pk}}$ values of the characteristic under study are 0.20 and 0.12 , which are far less than that for process to be capable, i.e., 1.33. Hence, the next

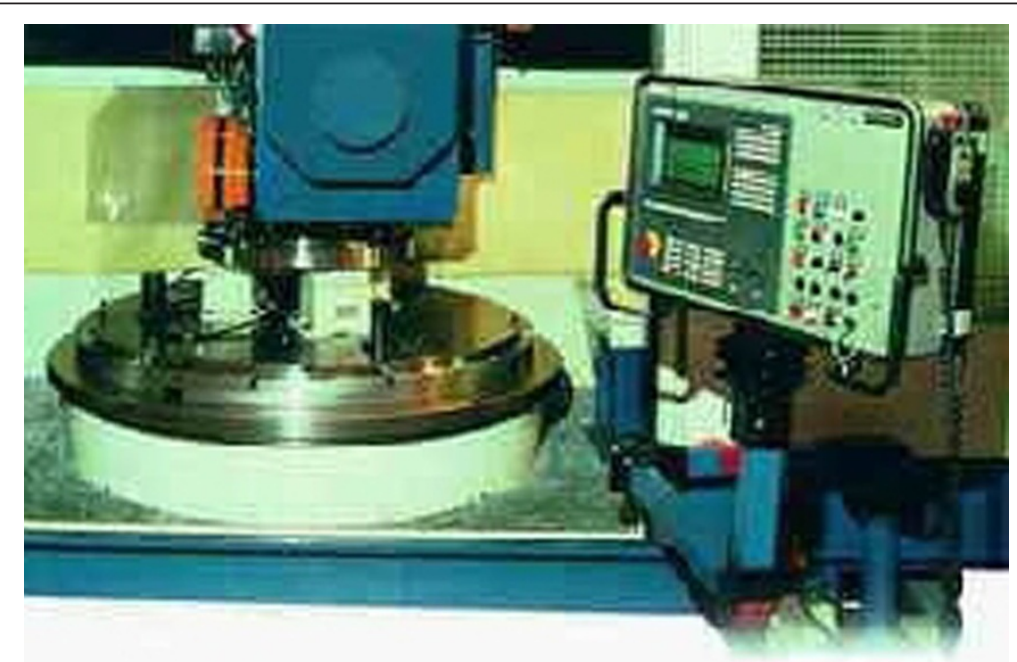

Figure 4 Machine loading and unloading platforms. 
Table 2 Process failure modes and effects analysis sheet

\begin{tabular}{|c|c|c|c|c|c|c|c|c|}
\hline Process name & $\begin{array}{l}\text { Potential } \\
\text { failure }\end{array}$ & Potential effect & Severity & Potential cause & Occurrence & Current controls & Detection & $\begin{array}{l}\text { Risk priority } \\
\text { number }\end{array}$ \\
\hline \multirow{7}{*}{$\begin{array}{l}\text { Rough grinding of } \\
\text { thrust face thickness } \\
\text { (operation no. 10) }\end{array}$} & \multirow[t]{4}{*}{$\begin{array}{l}\text { Thrust face } \\
\text { thickness more }\end{array}$} & \multirow{2}{*}{$\begin{array}{l}\text { Costly rework of the component } \\
\text { for attaining correct thrust face } \\
\text { thickness }\end{array}$} & \multirow[t]{2}{*}{9} & $\begin{array}{l}\text { In-process sensing gauge } \\
\text { malfunction }\end{array}$ & 7 & Gauge R\&R quality check point & 3 & 189 \\
\hline & & & & $\begin{array}{l}\text { Worn-out rest pads of the } \\
\text { fixture }\end{array}$ & 6 & Fixture calibration procedure document & 2 & 108 \\
\hline & & \multirow{2}{*}{$\begin{array}{l}\text { Incorrect location of the component } \\
\text { into the gudgeon pin boring fixture } \\
\text { in the next operation (no. 20) }\end{array}$} & \multirow[t]{2}{*}{9} & $\begin{array}{l}\text { Grinding wheel pads of the } \\
\text { fixture }\end{array}$ & 8 & $\begin{array}{l}\text { Grinding wheel dressing quality check } \\
\text { after production shift changeover }\end{array}$ & 2 & 144 \\
\hline & & & & $\begin{array}{l}\text { Grinding wheel setting } \\
\text { procedure not standardized }\end{array}$ & 5 & Tool setup control in the check list & 2 & 90 \\
\hline & \multirow[t]{2}{*}{$\begin{array}{l}\text { Thrust face } \\
\text { thickness less }\end{array}$} & \multirow[t]{2}{*}{ Component rejection } & \multirow[t]{2}{*}{6} & $\begin{array}{l}\text { Improper zero setting and } \\
\text { referencing of the grinding } \\
\text { wheel positioning }\end{array}$ & 6 & $\begin{array}{l}\text { Tool setup during shift changeover } \\
\text { procedure document }\end{array}$ & 1 & 36 \\
\hline & & & & Dial gauge not calibrated & 5 & $\begin{array}{l}\text { Gauge measurement system analysis } \\
\text { document }\end{array}$ & 1 & 30 \\
\hline & $\begin{array}{l}\text { Thrust face } \\
\text { unclean }\end{array}$ & Component rejection & 3 & $\begin{array}{l}\text { Dimensional inaccuracies of } \\
\text { forgings }\end{array}$ & 6 & Visual checkpoint & 1 & 18 \\
\hline
\end{tabular}


Table 3 Measured dimensions in tabular form

\begin{tabular}{|c|c|c|c|c|}
\hline Series number & Iteration 1 & Iteration 2 & Iteration 3 & Iteration 4 \\
\hline 01 & 26.000 & 26.500 & 27.250 & 27.250 \\
\hline 02 & 27.500 & 27.250 & 27.350 & 27.250 \\
\hline 03 & 27.250 & 27.250 & 27.350 & 27.250 \\
\hline 04 & 27.750 & 27.500 & 27.400 & 27.250 \\
\hline 05 & 27.400 & 27.400 & 27.200 & 27.300 \\
\hline 06 & 26.750 & 27.750 & 27.300 & 27.300 \\
\hline 07 & 27.000 & 27.000 & 27.250 & 27.300 \\
\hline 08 & 27.240 & 27.240 & 27.250 & 27.300 \\
\hline 09 & 27.300 & 27.300 & 27.300 & 27.300 \\
\hline 10 & 27.750 & 27.000 & 27.300 & 27.350 \\
\hline 11 & 26.250 & 26.750 & 27.350 & 27.350 \\
\hline 12 & 27.000 & 27.000 & 27.350 & 27.350 \\
\hline 13 & 27.000 & 26.900 & 27.450 & 27.350 \\
\hline 14 & 27.250 & 27.250 & 27.250 & 27.350 \\
\hline 15 & 27.250 & 26.900 & 27.200 & 27.400 \\
\hline 16 & 27.500 & 27.500 & 27.250 & 27.250 \\
\hline 17 & 27.500 & 27.500 & 27.250 & 27.250 \\
\hline 18 & 27.250 & 27.250 & 27.300 & 27.250 \\
\hline 19 & 27.750 & 27.750 & 27.250 & 27.250 \\
\hline 20 & 27.000 & 27.000 & 27.350 & 27.300 \\
\hline 21 & 26.750 & 26.750 & 27.350 & 27.300 \\
\hline 22 & 27.250 & 27.250 & 27.400 & 27.300 \\
\hline 23 & 27.250 & 27.250 & 27.200 & 27.300 \\
\hline 24 & 27.000 & 27.000 & 27.200 & 27.350 \\
\hline 25 & 27.500 & 27.500 & 27.300 & 27.350 \\
\hline 26 & 27.250 & 27.000 & 27.250 & 27.350 \\
\hline 27 & 27.220 & 26.900 & 27.300 & 27.350 \\
\hline 28 & 27.220 & 27.250 & 27.300 & 27.400 \\
\hline 29 & 27.250 & 26.900 & 27.350 & 27.250 \\
\hline 30 & 27.200 & 27.500 & 27.350 & 27.250 \\
\hline 31 & 26.500 & 27.500 & 27.400 & 27.250 \\
\hline 32 & 26.500 & 27.250 & 27.200 & 27.250 \\
\hline
\end{tabular}

set of data is captured after performing measurement system analysis (MSA) studies in iteration 2 of SPC studies for the KPC under study.

\section{Iteration 2}

In this iteration, the data is collected after gauge repeatability and reproducibility (GR\&R) was performed for the dial gauge and calibration of the dial gauge as a part of the measurement system analysis procedure. From the set of data in Table 3, it is seen that there is a marginal increase of $C_{\mathrm{p}}$ from 0.20 to 0.28 and $C_{\mathrm{pk}}$ from 0.12 to 0.21 . This marginal increase is a positive sign, but still, the process is not capable as both $C_{\mathrm{p}}$ and $C_{\mathrm{pk}}$ are far less than the desired value of 1.33. This calls for another iteration.

\section{Iteration 3}

In this iteration, data is collected after machine preventive maintenance schedule completion and replacement of grinding shoes of the machine as well as rest pads of the fixture. From the set of data in Table 4, it is seen that there is a noticeable increase of $C_{\mathrm{p}}$ from 0.120 to 1.23 and $C_{\mathrm{pk}}$ from 0.21 to 0.99 . This increase is a positive sign, but still, the process is not capable as both $C_{\mathrm{p}}$ and $C_{\mathrm{pk}}$ are far less than the desired value of 1.33 . This calls for another iteration, i.e., iteration 4 .

\section{Iteration 4}

This iteration tackles the 'tool wear compensation' cause. It is a common phenomenon that as any machining operation progresses, there is a calculated wear of the cutting tool responsible for the machining operation. The grinding operation here is no such exception. Hence, here the data was collected after presetting the value for the tool wear compensation knob at $15 \mu \mathrm{m}$ on the control panel of the machine. This means that after every wear out of $15 \mu \mathrm{m}$ of the grinding shoes, the grinding wheel surface is lowered by $15 \mu \mathrm{m}$ in order to compensate for the tool wear so that the dimensions of the product being machined will remain unchanged.

\section{One-way ANOVA method}

The one-way ANOVA method of investigation is adopted to test for the differences between the four iterations of data collected.

\section{Procedure describing one-way ANOVA}

In general, one-way ANOVA technique is used to study the effect of $k(>2)$ levels of a single factor. A factor is a characteristic under consideration thought to influence the measured observations, and level is a value of the factor.

To determine if different levels of the factor affect measured observations differently, the following hypotheses are to be tested:

$$
H_{0}: \mu_{i}=\mu \text { all } i=1,2,3,4
$$

$H_{1}: \mu_{i} \neq \mu$ for some $i=1,2,3,4$, where $\mu_{i}$ is the population mean for level $i$ and $\mu$ is the overall grand mean of all levels.

Here we have four levels (i.e., four iterations), and each level consisted of 32 measurement readings of thrust face thickness of the connecting rod. The sum, sum of squares, mean, and variance for each iteration are tabulated in Table 5. 


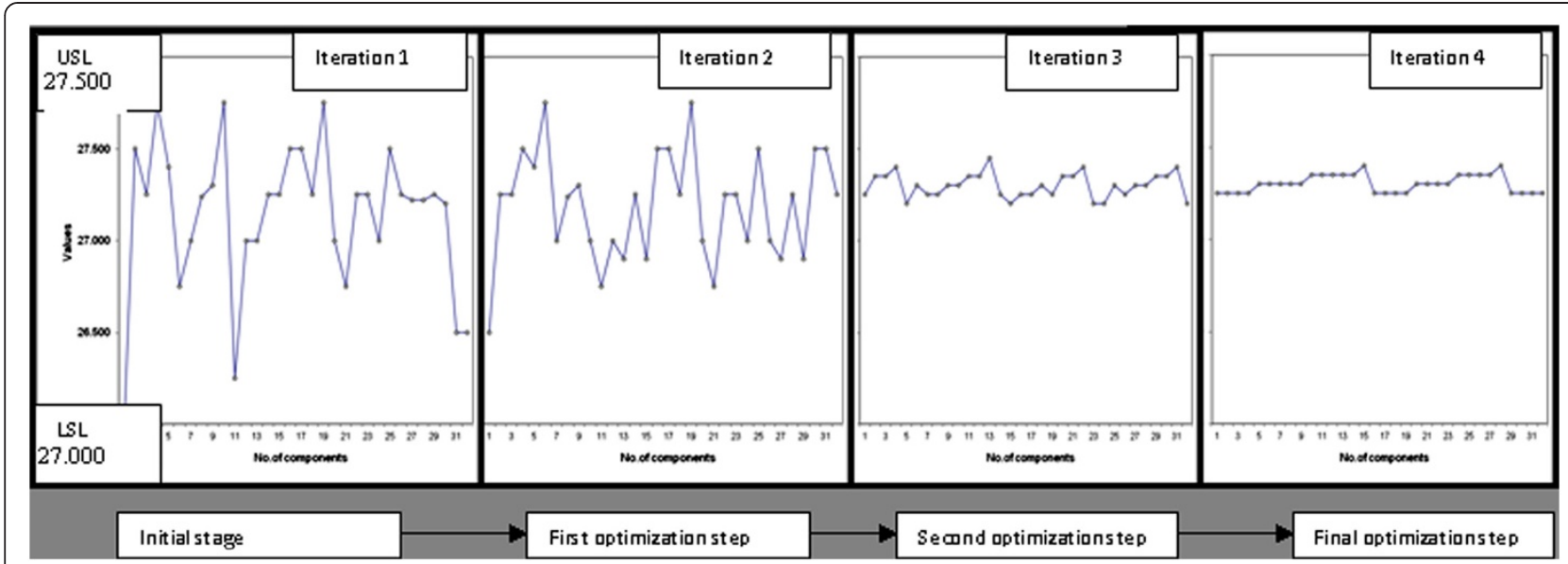

Figure 5 Process monitoring charts.

If $x_{i j}$ denotes the data from the $i$ th level and $j$ th observation, then the overall or grand mean is given by

$$
\mu=\sum_{i=1}^{4} \sum_{j=1}^{32} \frac{x_{i j}}{N}
$$

where $N$ is the total sample size of all four iterations, i.e., $32 \times 4=128$. Hence, from Equation 5, we get $\mu=27.233$.

The sum of squared deviations about the grand mean across all $N$ observations is given by

$$
\operatorname{SST}_{T}=\sum_{i=1}^{4} \sum_{j=1}^{32}\left(x_{i j}-\mu\right)^{2}
$$

The sum of squared deviations for each level mean about the grand mean is given by

$$
\mathrm{SST}_{L}=\sum_{i=1}^{4} 4 \times\left(\mu_{i}-\mu\right)^{2}
$$

The sum of squared deviations for all observations within each level from that level mean summed across all levels is given by

$$
\operatorname{SST}_{E}=\sum_{i=1}^{4} \sum_{j=1}^{32}\left(x_{i j}-\mu_{i}\right)^{2}
$$

From Equations 6, 7, and 8, the values of $\mathrm{SST}_{7}, \mathrm{SST}_{G}$, and $\mathrm{SST}_{E}$ obtained are 8.694, 0.55289, and 8.084, respectively.

On dividing $\mathrm{SST}_{T}, \mathrm{SST}_{L}$, and $\mathrm{SST}_{E}$ by their associated degrees of freedom $(d f)$, we get the mean of squared deviations, respectively. Hence, the mean of squared deviations between levels is given by

$$
\mathrm{MST}_{L}=\frac{\mathrm{SST}_{L}}{d f_{L}}=\frac{0.55289}{(4-1)}=0.184
$$

The mean of squared deviations within levels is given by

$$
\mathrm{MST}_{E}=\frac{\mathrm{SST}_{E}}{d f_{E}}=\frac{2.94}{(128-4)}=0.065
$$

Finally, the $F$ statistic is given by the following formula:

$$
F_{\text {statistic }}=\frac{\mathrm{MST}_{L}}{\mathrm{MST}_{E}}=\frac{0.98}{0.065}=15.07
$$

On summarizing all the above values in tabular form, the ANOVA table is obtained as shown in Table 6.

An $\alpha$ value of 0.05 is typically used, corresponding to $95 \%$ confidence levels. If $\alpha$ is defined to be equal to 0.05 , then the critical value for the rejection region is $F_{\text {critical }}$ $(\boldsymbol{\alpha}, \boldsymbol{K}-\mathbf{1}, N-K)$ and is obtained to be 2.677. Thus,

$$
F_{\text {critical }}=2.677
$$

From Equations 10 and 11, it is seen that

$$
F_{\text {statistic }}>F_{\text {critical }}
$$

Therefore, the decision will be to reject the null hypothesis. If the decision from the one-way analysis of variance is to reject the null hypothesis, then it indicates

Table 4 Calculations of $C_{p}$ and $C_{p k}$

\begin{tabular}{lcccc}
\hline Formula & Iteration & Iteration & Iteration & Iteration \\
& $\mathbf{1}$ & $\mathbf{2}$ & $\mathbf{3}$ & $\mathbf{4}$ \\
\hline $\mathrm{USL}$ & 27.500 & 27.500 & 27.500 & 27.500 \\
$\mathrm{LSL}$ & 27.000 & 27.000 & 27.000 & 27.000 \\
$\sigma$ & 0.408 & 0.296 & 0.068 & 0.048 \\
$C_{p}=\frac{(U S L-L S L)}{6 \sigma}$ & 0.20 & 0.28 & 1.23 & 1.72 \\
$C_{\mathrm{pku}}=\frac{(\mathrm{USL}-\text {-mean })}{3 \sigma}$ & 0.29 & 0.35 & 0.99 & 1.37 \\
$C_{\mathrm{pkl}}=\frac{(\text { mean-LSL) }}{3 \sigma}$ & 0.12 & 0.21 & 1.47 & 2.08 \\
$C_{\mathrm{pk}}=$ min $\left(C_{\mathrm{pku}} C_{\mathrm{pkl}}\right)$ & 0.12 & 0.21 & 0.99 & 1.37 \\
\hline
\end{tabular}


Table 5 Mean and variance of all four iterations

\begin{tabular}{lcccc}
\hline Formula & Iteration $\mathbf{1}$ & Iteration 2 & Iteration 3 & Iteration 4 \\
\hline Sample size & 32 & 32 & 32 & 32 \\
Sum & 868.580 & 870.040 & 873.550 & 873.650 \\
Sum of squares & $23,581.139$ & $23,658.01$ & $23,846.69$ & $23,852.08$ \\
Mean $\left(\mu_{i}\right)$ & 27.143 & 27.189 & 27.298 & 27.302 \\
Variance $\left(\sigma^{2}\right)$ & 0.166577 & 0.08734 & 0.004594 & 0.002336 \\
\hline
\end{tabular}

that at least one of the means $\left(\mu_{i}\right)$ is different from the other remaining means. In order to figure out where this difference lies, a post hoc ANOVA test is required.

\section{Post hoc ANOVA test}

Since here the sample sizes are the same, we go for Tukey's test for conducting the post hoc ANOVA test. In Tukey's test, the honestly significant difference (HSD) is calculated as

$$
\mathrm{HSD}=q \sqrt{\frac{\mathrm{MST}_{E}}{n}}=3.63 \sqrt{\frac{0.065}{32}}=0.16
$$

where $q$ is the studentized range statistic which is equal to a value of 3.63 , for a degree of freedom of 124 and $k=4$. The difference between the individual mean values of the four iteration levels can be summarized in a tabular form as shown in Table 7.

In Table 7, the absolute difference is of concern, and so the negative signs are to be ignored. Also in Table 7 , it is seen that the difference of $\mu_{1}-\mu_{4}=0.16$, which is equal with that of the HSD in Equation 14. Hence, it is concluded that the mean set of data between iteration 1 and iteration 4 is statistically significant when compared to the rest. Thus, it is concluded that among all the different causes enumerated in the cause-and-effect diagram, the most influencing cause is the tool wear compensation correction for the measurement data of iteration 4.

\section{Improve and control phase}

In this phase, the process monitoring charts are regularly employed for monitoring of the thrust face thickness of the connecting rod. In addition, gauge calibration is done periodically as a part of measurement system analysis, and properly calibrated gauges are used at the work place.

Table 6 ANOVA table

\begin{tabular}{lcccc}
\hline Source of variation & $\boldsymbol{d} \boldsymbol{f}$ & Sum of squares & Mean of squares & $\boldsymbol{F}$ \\
\hline Level & 3 & 0.55289 & 0.184 & 2.83 \\
Within/error & 124 & 8.084 & 0.065 & \\
Total & 127 & 8.694 & & \\
\hline
\end{tabular}

\section{Result and discussion}

As part of standardizing the process, the following activities were carried out:

1. The tool wear compensation knob which does not have any graduations was calibrated, and graduations were engraved at a $90^{\circ}$ interval

2. Proper fixture maintenance and machine maintenance schedule were established, and regular checks were included in the check lists

3. After every 12,000 components, the grinding shoes need to be replaced

4. Coolant recirculation pressure was set at a value of around $15 \mathrm{~kg}$ of force

After incorporating the above actions in the manufacturing control plan, the same procedure can be horizontally deployed for solving of pragmatic problems of similar nature.

\section{Conclusion}

SPC studies were found to be useful for eliminating the special cause of errors, streamlining the process, and making the process a capable manufacturing process by improving the $C_{\mathrm{p}}$ and $C_{\mathrm{pk}}$ values of the key quality characteristic under study. The cause-and-effect diagram formed an important scientific tool for enlisting the causes behind the poor performance of the process. On adapting the DMAIC approach, the estimated standard deviation ' $\sigma$ ' of the thrust face thickness is reduced from 0.408 to 0.048 , while the process performance capability index $C_{\mathrm{pk}}$ is enhanced from 0.12 to 1.37 .

The $C_{\mathrm{p}} / C_{\mathrm{pk}}$ values after performing the few iterations of data collection were greater than 1.33, and hence the process was declared as a capable process. After performing the root cause analysis, the major root cause, confirmed by the one-way ANOVA technique, was the improper setting of the tool wear compensation knob followed by the replacement of worn-out fixture rest pads for the thrust face grinding KPC. Hence, the oneway ANOVA technique was employed successfully for identification of the root cause liable for the low process capability.

Table 7 Differences of means between any two iterations

\begin{tabular}{lcc}
\hline Difference & Computation & Numerical value \\
\hline$\mu_{1}-\mu_{2}=$ & $27.143-27.189$ & -0.046 \\
$\mu_{1}-\mu_{3}=$ & $27.143-27.298$ & -0.155 \\
$\mu_{1}-\mu_{4}=$ & $27.143-27.302$ & -0.16 \\
$\mu_{2}-\mu_{3}=$ & $27.189-27.298$ & -0.109 \\
$\mu_{2}-\mu_{4}=$ & $27.189-27.302$ & -0.113 \\
$\mu_{3}-\mu_{4}=$ & $27.298-27.302$ & -0.004 \\
\hline
\end{tabular}




\section{Competing interests}

The authors declare that they have no competing interests.

\section{Authors' contributions}

GVSSS collected the required data of the Key Quality Characteristic, participated in the Failure Modes and Effects Analysis and performed the statistical analysis. PSR conceived of the study and participated in its analysis, design and coordination. All authors read and approved the final manuscript.

\section{Acknowledgments}

The authors are thankful to M/s AVTEC Limited of pithampur Industrial area, Madhya Pradesh State, India, for facilitating in the data collection for the present process capability improvement study.

\section{Author details}

'Department of Mechanical Engineering, GMR Institute of Technology, GMR Nagar, Rajam-532127, Andhra Pradesh State, India. ${ }^{2}$ Department of Industrial Engineering, GITAM Institute of Technology, GITAM University,

Visakhapatnam - 530045 Andhra Pradesh State, India.

\section{Received: 22 July 2013 Accepted: 10 November 2013}

\section{Published: 06 Dec 2013}

\section{References}

Chen W-L, Huang C-Y, Huang C-Y (2013) Finding efficient frontier of process parameters for plastic injection molding. J Ind Eng Int 9:25, doi:10.1186/2251$712 X-9-25$

Gentili E, Aggogeri F, Mazzola M (2006) The improvement of a manufacturing stream using the DMAIC method. University of Brescia Paper No. IMECE200614469. ASME, New York, pp 127-133, doi: 10.1115/IMECE2006-14469

Hwang Y-D (2006) The practices of integrating manufacturing execution system and six sigma methodology. Int J Adv Manuf Technol 30:761-768, doi:10.1007/s00170-005-0090-1

Kumaravadivel A, Natarajan U (2013) Application of six-sigma DMAIC methodology to sand-casting process with response surface methodology. Int J Adv Manuf Technol, doi:10.1007/s00170-013-5119-2

Li M-HC, Al-Refaie A, Yang C-Y (2008) DMAIC approach to improve the capability of SMT solder printing process. IEEE Trans Electron Packag Manuf 31:126

Lin H-C (2004) The measurement of a process capability for folded normal process data. Int J Adv Manuf Technol 24:223-228, doi:10.1007/s00170-0031615-0

Lin SJ, Yang DL, Cheng FT, Wu MF (2013) Aircraft turbine engine manufacturing with multiple specifications. J Test Eval 41(1):1-7, doi:10.1520/JTE20120022

Locke JW (1994) Statistical measurement control, quality and statistics. In: Milton Kowalewski I Jr (ed) Total quality management, ASTM STP 1209. American Society for Testing and Materials, Philadelphia

Sahay C, Ghosh S, Bheemarthi PK (2011) Process improvement of brake lever production using DMAIC. University of Hartford, Paper No. IMECE2011-63813. ASME, New York, pp 801-826, doi:10.1115/IMECE2001-63813

Schilling EG (1994) The transition from sampling to SPC, quality and statistics. In: Milton Kowalewski J Jr (ed) Total quality management, ASTM STP1209. American Society for Testing and Materials, Philadelphia

Sharma GVSS, Rao PS, Jagadeesh V, Vishwakarma A (2013a) Process capability improvement - a case study of an engine connecting rod manufacturing process. Int J Mech Eng Technol (IJMET) 4(5):116-129

Sharma GVSS, Rao PS, Jagadeesh V, Vishwakarma A (2013b) Process capability improvement - a case study of crank-pin bore honing operation of an engine connecting rod manufacturing process. Int J Adv Res Eng Technol (IJARET) 4(6):84-97

Singh R (2011) Process capability study of polyjet printing for plastic components. J Mech Sci Tech 25(4):1011-1015

Tong JPC, Tsung F, Yen BPC (2004) A DMAIC approach to printed circuit board quality improvement. Int J Adv Manuf Technol 23:523-531, doi:10.1007/ s00170-003-1721-z

\subsection{6/2251-712X-9-37}

Cite this article as: Sharma and Rao: Process capability improvement of an engine connecting rod machining process. Journal of Industrial Engineering International 2013, 9:37 